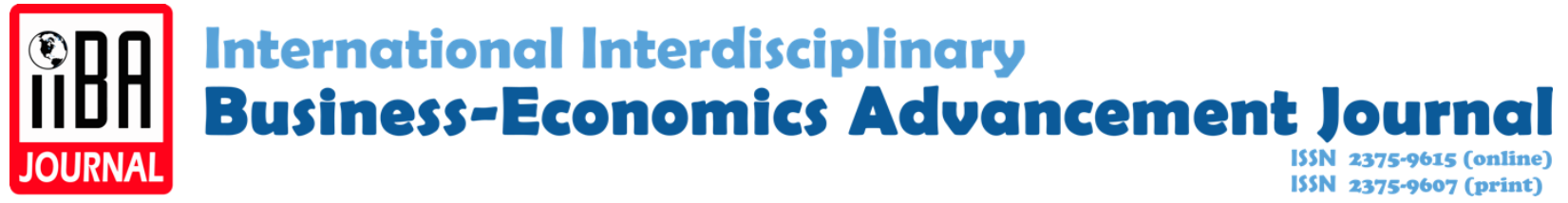

Volume 2 Issue 2

Article 3

\title{
Chinese dream and middle way limits
}

Boyan Ivantchev

University of National and World Economy

\section{Recommended Citation}

Ivantchev, B. (2017). Chinese dream and middle way limits. International Interdisciplinary Business-Economics Advancement Journal, 2(2), 95-103.

\section{Revisions}

Submission date: Sep. 6, 2016

1st Revision: Jun. 20, 2017

2nd Revision: Jul. 7, 2017

Acceptance: Jul. 10, 2017 


\title{
Chinese Dream and Middle Way Limits
}

\author{
Boyan Ivantchev
}

\author{
Department of Economics \\ University of National and World Economy, Bulgaria \\ ivantchev@omega.bg
}

\begin{abstract}
Until 1978 China had a class struggling model of development. After years of bad experience, it was only natural to leave that model and to focus on the economical development of the country The Ruling party of China decided to take The Middle Way of economical development, combining the leading role of the communist party and capitalistic market economy. Chinese people were used to The Middle Way because of ancient history, local psychology and the prevailing mixture of Daoist and Confucian philosophy. The philosophical and psychological tendency of Chinese people to tend to find a Middle Way and reasoning, is very much different than the western thinking, which is based on finding always right way and contradiction. In this paper, we will discuss foundations and limitations of the Chinese Middle Way Model and whether it is really the most natural way for China. Also, we are trying to foresee the future development of the Chinese model and the limitations of the Middle Way Reasoning and its implications to the growth and exponentiality of the 21 st century.
\end{abstract}

Keywords: middle way limits, two in two model, Chinese future

\section{Introduction}

Many scholars and politicians are trying to explain, attack or promote the Asian rise and especially - the Chinese economical development, of the past few decades (Franklin, Jun, \& Meijun, 2005; Krugman, 2016; Lin, Cai, \& Li, 2003; Naughton, 2006; Yuanyuan \& Jing, 2012). Some explain it with the specifics of the Chinese culture and especially - with the willingness of people to work longer hours for less money. Others try to explain it by comparing it to the weaker western society, its economical and political problems, and its capitalistic crisis. Since the 1990s some researches discussing the Chinese miracle, have been showing quantitative forecasts of China outpacing USA in terms of GDP. One of the mistakes scholars make in terms of the understanding the Chinese rise is the predominant basing of their analyses and forecasts to quantitative indicators. They are not focused on the findings and limitations coming from the nature of Chinese religion, philosophy, culture, and the Chinese way of reasoning.

Current paper intends to find a different approach to explaining this transition model and to the future development of the country. The transition to the new model of economical and social development is explainable trough the complex Chinese culturology which despite the diversity of Chinese communities and religions, holds many shared and persisting national characteristics. Chinese religion, philosophy and culturology, by its nature, is not anchoring the Chinese population to certain monotheistic religious believes and behaviours. Additionally, this is a result of a really low level of religiosity in China. Many of the Chinese people neither believe in a higher power, nor identify with any particular faith (Yang, et al., 2007; Sun, 2013) which does 
not contradict with the state atheism of the ruling Communist Party of China. Thus, there was a relatively smooth culturological base for adapting to the rapid and serious socioeconomic changes of the emergence and development of the transition model in China a model based on the dual philosophical-religious and political system, and on The Middle Way Reasoning.

\section{Foundations of the Chinese Economic Model}

The first pillar of the model is based on the collectivistic and centralized way of life and the Confucianism. Main features of the first pillar are: the importance of family and hierarchy of social life and political system, cultivation of morality and self-restraint, and the emphasis on hard work and achievements - "A young man should be filial within his home and respectful of elders when outside, should be careful and trustworthy, broadly caring of people at large, and should cleave to those who are ren. If he has energy left over, he may study the refinements of culture (wen)." (Confucius, 1979, p. 1-2). Thus, in the Confucians way of thinking there is a natural applicability of the collectivism of communistic ideology and the central governance of the ruling Communist Party of China.

Second pillar of the model is based on Daoism as a philosophy and a religion with the following features: Daoism represents more personal and metaphysical preoccupations, stating importance of the natural way and harmony with the environment. Daoists do not believe in extremes, instead they focus on the interdependence of things. There is no absolute good or evil, negative or positive. The Yin-Yang symbol exemplifies this view. The symbol shows that within the Yang there exists the Yin and vice versa - "Yin and Yang between heaven and earth unite to drip sweet dew. Without any command from the people, it drips evenly over all" (Cai, 2009, p. 123). nature is the balance between the two, thus there is natural applicability of market economy and entrepreneurship into the collectivist Confucian and communist society.

The third pillar of the model is based on the Chinese Middle Way Reasoning: this is the natural way of reasoning for the Asian nation and at the same time - different than the western reasoning. Western thinking is based on always finding the right way and contradiction, contrary to Chinese way of thinking, which is ideographic and based more on synthesizing than analysing. Furthermore, according to Peng and Nisbett (1999), "when two apparently contradictory propositions were presented, American participants polarized their views, and Chinese participants were moderately accepting of both propositions" (p. 741). Analogy and the use of historical examples (Kirkpatrick, 2005) are also typical for China, as well as persuasive arguments in Asian cultures and China are indirect and inductive, while Western cultures use a deductive method of reasoning. Middle Way Reasoning is also influenced by Chinese rhetoric in general (Garett, 1993a; Garett, 1993b; Garett, 1998; Lipson \& Binkley, 2004) and rhetorical techniques such as chain reasoning (If $\mathrm{P}$, then $\mathrm{Q}$. If $\mathrm{Q}$, then $\mathrm{R}$. Therefore, If $\mathrm{P}$, then $\mathrm{R}(\mathrm{P} \rightarrow \mathrm{Q}$. $\mathrm{Q} \rightarrow \mathrm{R}$. Therefore, $\mathrm{P} \rightarrow \mathrm{R}$ ).

\section{Experimental Laboratories for the Market Reforms and Chinese Ideographic Thinking}

Ideographic writing and ideographic thinking is based on image and picture, and is derived from the Chinese linguistics and characters. "Chinese people tend to think based on image and pictures. Chinese characters originate from imitation of the shape or features of the objects. They are called ideographs" (Liu, 2015, p. 5). Another confirmation for the important role of ideographic thinking and the need of experimental laboratories, comes from Boroditsky 
"Language can be a powerful tool for shaping abstract thought. When sensory information is scarce or inconclusive languages may play the most important role in shaping how their speakers think" (Boroditsky, 2001, p. 20).

Phonetic writing and phonetic thinking in western cultures leads to an imaginative, analytic and straightforward thinking, contrary to the paratactic tendency of Chinese language and Chinese thinking, where synthesis and circulative thinking are prevailing. In the last decade, numerous neuroscientists and cultural neuroscientists have shown existing differences between American and Chinese cultures, and how the environment and beliefs shape cognitive function (Azar, 2010).

At the beginning of 1978, China was far from a modern society where the law of supply-anddemand rules market economy. Limitations of the Chinese ideographic thinking and middle way approach leads to the only one, scientifically right way for reforms and applying novelties in Chinese society - usage of economical experiments and economical labs. The need of experiments and laboratories was further determined by the long-lasting history of isolation in China, which separated the country of the latest economic and scientific trends. Hence, there was a need to conduct real experiments, before adopting big socioeconomic reforms. In this paper, we call these experiments Experimental Laboratories for the Market Reforms.

The author believes that the first such Experimental Laboratory became Special Economic Zone in the town of Shenzhen. Special Economic Zone in Shenzhen was used as an ideogemma to help Chinese people and the Communist Party in the understanding of western economic achievements and free market rules. Central Government of the CPC needed to prove the usability and sustainability of laboratories for China and the collectivistic Chinese society; and afterwards to use the laboratory results for its future reasoning and long-term strategy, creating megatrends for the whole country in the next decades.

Combining the two local philosophies and religions (Confucianism and Daoism), and the two imported ideologies (collectivistic communism and capitalistic market economy and entrepreneurship) gives the actual Chinese model of development. The author calls that model Two in Two Model, which is derived from the philosophical and psychological tendency of Chinese people to combine opposite ideologies, and the intrinsic middle way choice and middle way reasoning.

There are certain limitations of the Two in Two Model and middle way reasoning. These limitations are derived from its culturological features and limitations of Chinese way of thinking and reasoning and its future progressive abilities. Let us explore how Two in Two Model is predesignated to be a quantitative approach and what are limitations of the inductive reasoning in China.

\section{Main Steps of Transition Made in China After 1978}

Here in this paper, the author is calling the first step of the transition was From Planned Economy to Market Commercial Economy with a Plan. The Chinese approach to the market transition has been well researched by many scholars in the past (Brandt \& Rawski, 2008; Garnaut \& Huang 2001; Naughton, 2006). The process began in the rural regions where people started making their own decision on what to produce. Chinese people started dividing the land 
between single households voluntarily. However, the ownership of the land was the same as before. That was the introduction of the household responsibility system started in Anhui Province. Peasants shortly realized that they know market requirements, demand, and people's needs better than the centralized and planned economy. Soon the new approach yield good results for the peasants. It was not until late 1980s that the Communist Party would officially allow the household responsibility system to exist but only in poor areas. The Communist Party started promoting actively the household responsibility system in early 1982. By the end of 1982, 80 per cent of households adopted the new system nationwide (Qian, 2000). Since then, based on these promising experimental results, the same approach was adopted by the city regions in China and collectively owned enterprises.

The second step of the transition is called in the paper Open Door Policy to the Rest of the World. Opening to the world started with easiest and most natural way for China. The process began in late 1979 on the coastal territory, in the town of Shenzhen where the first Special Economic Zone (SEZ) was established as the first real experimental lab for market economy in China. The SEZ in Shenzhen was bordering with Hong Kong a territory from which to exemplify, learn and copy the market economy rules and relationships. Through this Chinese SEZ was attracting FDIs, allowing infusion of new technologies, production, and labour organization. Thus, Chinese manufacturing and export backbones was starting to form. After the success of the experimental lab in Shenzhen, new economic model was replicated in three more SEZ, established in the same region. In 1981 the first four Chinese SEZ were responsible for the very impressive 60 per cent of the total FDI's in the country (Yeung, Lee \& Kee, 2009). Successful experiments led to replicating same model of development in other coastal cities and later in China's mainland.

After fourteen years of successful market economy lab experiments, Deng Xiaoping made an important statement: "Market economy doesn't equal to capitalism and market economy is also needed by socialist countries" (Vogel, 2011, p. 667). This statement exemplifies in the best possible way the meaning of Two in Two Model. As a result, at the $14^{\text {th }}$ congress, during the October 1992 Chinese Communist Party made a decision to establish Socialist market economy, hence Chinese middle way. The success of the Experimental Laboratories for the Market Reforms was officially reconfirmed and adopted by the Central Government as a backbone for the future development of Chinese society. The process of opening up From Outside to Inside of China continued from small coastal cities to cantons, provinces and central authorities. SEZ and afterwards industrial zones become the main driver of Chinese rise for the past 35 years, attracting FDI's, technologies and strengthening its base for export oriented manufacturing and international trade policy.

Here we call the third step of the transition From Inside to Outside. This is because opening up From Outside to Inside led to a successful creation of the export backbone of the industry in China and future economical acceleration needed more and new export markets and active political intervention from the Chinese state. On the $11^{\text {th }}$ of December 2001 China become a $143^{\text {rd }}$ member of World Trade Organisation (WTO) and the former Chinese President Hu Jintao stated "China's accession to the WTO is a milestone in China's reform and opening up, bringing us into a new era to further open up. To join the WTO was a major strategic decision based on our comprehensive analysis of the situation at home and abroad in order to push forward China's 
reform and opening-up and socialist modernization" (WTO, 2011, p. 3). The Chinese rulers and the communist party believed, that further acceleration of the country export and GDP growth inevitably requires WTO membership. That was a simple continuation of copying the model of the surrounding Asian economic tigers and their GATT/WTO membership from $80-90$ s of $20^{\text {th }}$ century. WTO target is exemplifying, for consecutive time, typical Chinese way of chain reasoning and as per the author of the current paper, it can be exemplified as follows: If a country is a WTO member, then that country is exporting more. If a country is exporting more, then the country will be reach. Therefore, if a country is a WTO member, then the country will be rich (WTO, 2011).

Opening the country up, From Inside to Outside, required changes of the fixed exchange rate of the Yuan. In 2005, China liberalized fixed currency exchange rate system and introduced narrow trading band starting from $\pm 0,3$ up to $\pm 2 \%$ until March 2014. Since 2015, Central Bank of China introduced new exchange rate system, which allows daily fluctuations $\pm 2 \%$ from the central bank daily fixing. So far this is still an important tool and additional support to the Chinese export expansion.

As a part of further increasing export and foreign trade relations, this country introduced a strategy to build a wide chain of Free Trade Agreements with as much as possible partners. Actual China's FTA's are as follows: China-Australia, China-Korea, China-Switzerland, ChinaIceland, China-Costa Rica, China-Peru, China-Singapore, China-New Zealand, China-Chile, China-Pakistan, China-ASEAN, Mainland and Hong Kong Closer Economic and Partnership Arrangement, Mainland and Macau Closer Economic and Partnership Arrangement. Nowadays, there are many other agreements being currently negotiated.

Consecutive Chinese step produced by From Inside to Outside to support the export possibilities of the country, was establishing and joining BRIC and afterwards BRICS. Through this initiative of the Chinese government, next stage of the opening up model - From Inside to Outside - was formalized and confirmed. China and BRICS countries tried to reshape the world rules in the field of reserve currencies, World Bank and IMF, forming New Development Bank and supporting international transactions in local currencies of the BRICS, targeting bigger exports and independence from the world reserve currencies USD and EUR. Secondly, BRICS initiative was an attempt to find a way to avoid ruling the Society for Worldwide Interbank Financial Telecommunication (SWIFT) system of interbank payments. This is probably the latest quantitative strategy of synthesis and chain reasoning for the Chinese state.

There is some evidence that last years, during the new normal GDP growth (6.5-7\%) in China From Inside to Outside model targeted higher wages for achieving bigger internal demand and bigger portion of internally created GDP. Simultaneously modernization of China was inevitably and naturally accompanied by the process of urbanization - consecutive target for the Chinese rulers. The urbanization process led to a creation of 30 big cities each one with more than 8 million people, among which 13 cities with more than 13 million people. However, the real rate of urbanization is around 38 per cent because of the seasonal and migrant characteristics of many of the workers who are not permanent city residents. In the near future, Chinese government believes, that urbanization will fuel internal demand and relocation costs, what might support GDP growth. 


\section{First Qualitative Targets and Less Tight Society}

In the case of old normal developments of the societies and the world economy, inductive reasoning and chain thinking can be applied and reshaped in case of failure or success of the experimental results, what is the only form to prove the inductive hypothesis. But in the realm of the new normal - multipolarity in the world politics and international economics - chain reasoning is not applicable. Rising uncertainty across the world and exponential development of the future and Artificial Intelligence (AI) is decreasing China's disposable time for a lab experiments and pure quantitative approach. Thus, the author believes that usability of the quantitative approach and inductive reasoning, which requires experiments and longer time for proving the results, dramatically is diminishing and China will need to reshape and adjust Two in Two Model.

All great achievements, based predominantly on achieving quantitative indicators, pushed Chinese leaders to declare in 1997 (three years before planned), that the country achieved Welloff Society. In October 2002 on the 16th congress of Chinese communist party, a decision was made, that during the first 20 years of 21 st century China must concentrate on achieving WellOff Society in All-Round Way. Therefore, new quantitative indicators were set to be achieved till 2020. One of these indicators is to double the 2010 GDP at the end of 2020. Thus, next chain reasoning and believe that simple quantitative rising of GDP should lead to a sustainable economical development, wellbeing, and enhancing Chinese respect globally.

Sustainable economical development is a certain compromise between economic, environmental and social goals of the society, with main target - wellbeing for the current and future generations. Sustainability requires combination and compromises between quantitative and qualitative indicators and targets. But EU and US compromises are not comparable with Chinese issues of the day and lack political pluralism and limited citizens' rights. Many issues in this country are connected with dangerous food, heavily polluted environment, censured press, controlled democracy, securing food supply in the future, centralized corruption and many others. Shockingly good results of Chinese economy in the last 35 years are contradicting with the environmental-friendly development. The price paid for putting first quantitative targets and achieving 10 per cent average GDP growth for many years in a row is resulting in lower life expectancy in China. More than 60 per cent of underground waters pollution and country become the largest single emitter of greenhouses, having worst air pollution in the world according to Greenpeace East Asia Report in 2015. So, the future of China will require massive reshaping of its manufacturing base, international trade and FDIs for to decrease enormous pollution of the country (Shenggang, Baolong, \& Xiahong, 2014) and to achieve better qualitative and soft indicators for its people. At the time of resolving of some of the abovementioned issues will support wellbeing and quality of life in China and will ease social unrest. These issues already provoked officially 2,744 and unofficially 10,425 cases of protests and demonstrations for 2015 (Lin, 2016). So, the Chinese single party government in the last years has been trying to imitate reduced political intervention and influence in minor social issues in order to loose a bit $360^{\circ}$ society regulations. Since the mid of 2012 we can see a trend in China, supported by central government and coherent with the model From Inside to Outside, of creation of a variety of NGOs and think tank organizations, trying to widen local authorities' rights. Definitely this trend is not changing the Two in Two Model, but focuses on persuading people who are self-organized, but in the environment of no real political pluralism. Here we can 
see how tight is the quantitative Two in Two model and how big are the limitations in the sociopolitical scene.

\section{Conclusion: Two in Two Model vs. Exponentiality}

The European Union is still under way of negotiating a trade and investment deal with the US the Transatlantic Trade and Investment Partnership. The deal with USA will help to cut red tape barriers, that companies face when exporting and to set new rules to make it easier to export, import, and invest overseas with estimated potential gains for the EU as up to 119 billion EUR a year and 95 billion EUR for the US (European Commission, 2013a). The Foreign Trade Agreement between EU and Japan has a very similar purpose and will lead to more active trade between two parties. An agreement is expected to boost Europe's economy by 0.6 to 0.8 per cent of its GDP and will result in growth and the creation of 400,000 jobs. It is expected that EU export to Japan could increase by 32.7 per cent, while Japanese export to the EU would increase by 23.5 per cent (European Commission, 2013b). Side effects of these FTAs will substitute imported Chinese goods in the EU, USA and Japan. In the past few years, protectionists view on the international economics and trade have been rising and we have continuing foreign currency wars. Currently, the US administration is revising NAFTA and other free trade agreements and in the case of Sino-US relationships there is serious will from the Trump administration to reduce US trade deficit which reached 347 bn. USD in year 2016. Inter dependability and sensitivity of Chinese growth and foreign trade with developed countries and external shocks is still very significant. We can visualize it with Foreign Invested Enterprises (FIEs) in China. FIEs often (but not exclusively) are joint ventures between foreign companies and Chinese enterprises and account for over 50 per cent of China's export and 60 per cent of its import and are heavily oriented to the export to developed markets. Their share in Chinese GDP has been reaching some 20 per cent but employing only 3 per cent of the workforce, because of the higher average labour productivity, around 9 to 1 comparing to the Non-FIEs (Whalley \& Xin, 2010). Thus, large export oriented manufacturing industry in China will face big problems, causing slower Chinese GDP growth in the future. Resolving environmental issues of the day in China also will be harmful for the pure quantitative indicators like GDP growth. This may provoke higher unemployment rate in China and social unrests. In the realm of no soft and qualitative developments, no freedom of press and democracy, the central government and the sole political party - the Communist Party of China - will be blamed for the failure of the economic model by the Chinese people. What might be really dangerous for the existing Chinese model.

The sensitivity of the Chinese model will accelerate in $21 \mathrm{st}$ century, because of the exponentiality and massive employment of AI and robots. In his famous paper The Law of Accelerating Returns, Kurzweil (2004) stated:

\footnotetext{
The paradigm shift rate (i.e., the overall rate of technical progress) is currently doubling (approximately) every decade; that is, paradigm shift times are halving every decade (and the rate of acceleration is itself growing exponentially). So, the technological progress in the twenty-first century will be equivalent to what would require (in the linear view) on the order of 200 centuries. In contrast, the twentieth century saw only about 25 years of progress (again at today's rate of progress) since we have been speeding up to current rates. So, the twenty-first century will see almost a thousand times greater technological change than its predecessor (para. 28).
}

The prerequisite for the exponential growth is the availability of the individual and societal free will of deductive thinking - based on the western reasoning - always to find the right way and 
contradiction. That prerequisite is missing in Chinese aesthetics and way of thinking because of the inner features of the Two in Two Model. The model always uses lab experiments, what can cause China to drop behind the exponentiality leaders in $21^{\text {st }}$ century within less than 10 years.

So far, as per the author of the this paper, Chinese counteraction to exponentiality is to rise Chinese deals by acquiring foreign companies (225 billion USD invested in 2016), using them as a new form of laboratories, trying to catch up with the innovations and exponential scientific development. But the centripetal forces of the ruling Communist Party of China are against this process. They believe it is drying internal investment possibilities. That is one of the points where Chinese decision-making will need deductive reasoning instead of inductive Chinese logic, and to go further with model From Inside to Outside.

\section{References}

Azar, B. (2010). Your brain on culture. Journal of the American Psychological Association, 41(10), 44-46.

Boroditsky, L. (2001). Does language shape thought? Mandarin and English speakers conceptions of time. Cognitive Psychology, 43, 1-22.

Brandt, L. \& Rawski, T. G. (Eds.). (2008). China's great economic transformation. Cambridge, MA: Cambridge University.

Cai, X. (2009). Wise man talking series: Lao Zi says. Beijing, China: Sinolingua.

Confucius (1979) The analects (classics) by Confucius, (D. C. Lau, Trans.). London, UK: Penguin Classics.

European Commission (2013a). Transatlantic trade and investment partnership: The economic analysis explained. European Commission. Retrieved from http://trade.ec.europa.eu/doclib/docs/2013/september/tradoc_151787.pdf.

European Commission (2013b). MEMO/13/572, 17/06/2013. European Commission. Retrieved from http://europa.eu/rapid/press-release_MEMO-13-572_en.htm.

Franklin, A., Jun, Q., \& Meijun, Q. (2005). Law, finance, and economic growth in China. Journal of Financial Economics, 77(1), 57-116.

Garett. M. M. (1993a). Classical Chinese conceptions of argumentation and persuasion. Argumentation and Advocacy, 29, 105-115.

Garett, M. M. (1993b). Pathos reconsidered from the perspective of classical Chinese rhetorical theories. Quarterly Journal of Speech, 79(1), 19-39.

Garett, M. M. (1998). In rhetoric in ancient China: Fifth to third century B.C.E. Columbia, SC: University of South Carolina.

Garnaut, R., \& Huang, Y. (2001). Growth without miracles: Readings on the Chinese economy in the era of reform. Oxford, UK: Oxford University.

Kirkpatrick, L. A. (2005). Attachment, evolution, and the psychology of religion. New York, NY: Guilford.

Krugman, P. (2016). When China stumbles. The New York Times. Retrieved from: https://www.nytimes.com/2016/01/08/opinion/when-china-stumbles.html?partner=rss\&emc=rss.

Kurzweil, R. (2004). The law of accelerating returns. Retrieved from https://www.edge.org/response-detail/10600.

Lin, J. Y., Cai, F., \& Li, Z. (2003). The China miracle: Development strategy and economic reform. Hongkong, China: Chinese University.

Lin, K. (2016). Rising inequality and its discontents in China. New Labor Forum, 25(3), 66-74.

Lipson, C. S. \& Binkley, R. A. (2004). Rhetoric before and beyond the Greeks. Albany, NY: Suny.

Liu, J. (2015). On the influences of different eastern and western thinking patterns on cross-cultural communication. Cross-Cultural Communication, 11(10), 5-8.

Naughton, B. (2006). The Chinese economy: Transitions and growth. Cambridge, MA: MIT.

Peng, K. \& Nisbett, R. E. (1999). Culture, dialectics, and reasoning about contradiction. American Psychologist, 54(9), 741-754.

Qian, Y. (2000). The process of China's market transition (1978-1999): The evolutionary, historical, and comparative perspectives. Journal of Institutional and Theoretical Economics, 156(1), 151-171.

Shenggang, R., Baolong, Y., Xie, M., \& Xiaohong, C. (2014). International trade, FDI and embodied CO2 emissions: A case study of China's industrial sectors. China Economic Review, 28(3), 123-134. 
Sun, A. (2013). Confucianism as a world religion: contested histories and contemporary realities. Princeton, NJ: Princeton University.

Vogel, E. F. (2011). Deng Xiaoping at the transformation of China. Cambridge, MA: Harvard University.

Whalley, J., \& Xin, X. (2010). China's FDI and non-FDI economies and the sustainability of future high Chinese growth. China Economic Review, 21(1), 123-135.

World Trade Organisation (WTO). (2011). China in the WTO: Past, present and future. Retrieved from https://www.wto.org/english/thewto_e/acc_e/s7lu_e.pdf.

Yang, F., Yuan, V., Sun, A., Yengfang, L., Stark, R, Johnson, B., Liu, E., \& Heu-Yuan, C. (2007). Spiritual life study of Chinese residents. Association of Religion Data Archives. Retrieved from http://www.thearda.com/Archive/Files/Descriptions/SPRTCHNA.asp.

Yeung, Y., Lee, J., \& Kee G. (2009). China's special Economic Zones at 30. Eurasian Geography and Economics, 50(2), 222-240.

Yuanyuan, W., \& Jing, Y. (2012). Corruption and firm growth: Evidence from China. China Economic Review, 23(2), 415-433. 